\title{
TOPICS ON REGENERATIVE PROCESSES
}

\author{
CRC Press, Boca Raton, 1994 (to appear) \\ VLADIMIR V. KALASHNIKOV \\ Institute of Systems Analysis, \\ 9, Prospect 60 let Oktyabrya, \\ 117312 Moscow, Russia \\ e-mail: mconeau@glas.apc.org \\ fax: (095) 938-2209
}

The aim of the book is to develop new mathematical methods for quantifying various characteristics of regenerative processes. The book consists of five chapters.

Chapter 1 considers classic (due to W. Smith) and weak (due to H. Thorisson) regenerations. These constructions are supplied with non-trivial examples (such as a multi-server queue in continuous time).

The important notions of "crossing" and "coupling" are studied in Chapter 2. Crossing is a more general notion than coupling, permitting one to compare regenerative processes which are not versions of each other.

Ergodic theorems equipped with estimates of the rate of convergence to the steady state are considered in Chapter 3. This chapter also contains comparison bounds which enable one to estimate uniform-in-time discrepancies between pre-stationary distributions of regenerative processes under comparison.

Chapter 4 evolves methods for obtaining bounds for the distribution function of the first-occurrence time of some event (like the first break-down time in reliability theory).

Chapter 5 contains various applications of the developed technique (general Markov chains, queueing models, reliability models, simulation).

Presented bounds have a correct order of accuracy and imply proper limiting results. They can be used as a basis for new Monte-Carlo algorithms permitting one to evaluate such "non-traditional" (in simulation) characteristics as the rate of convergence to the steady state and the first-occurrence time.

The book is intended for graduate students and specialists in the area of probability and operations research (including applied probability, theory of Markov processes, queueing, reliability and simulation). 


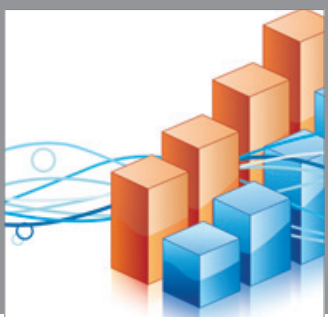

Advances in

Operations Research

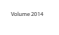

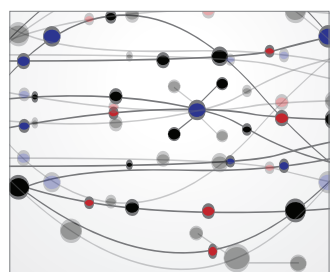

\section{The Scientific} World Journal
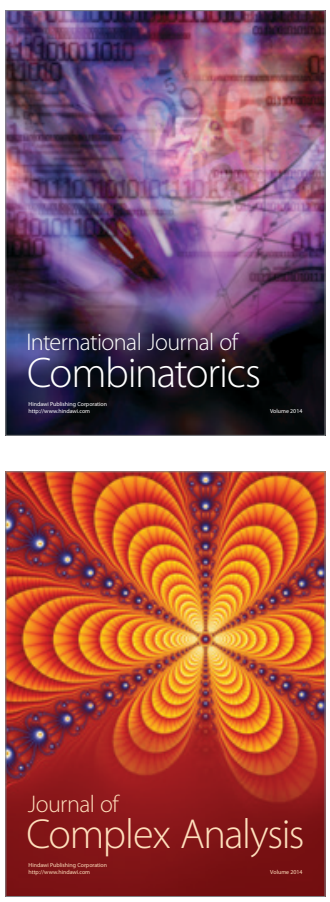

International Journal of

Mathematics and

Mathematical

Sciences
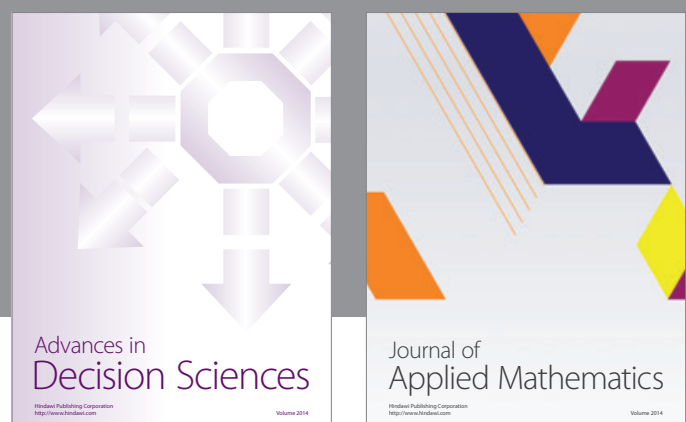

Journal of

Applied Mathematics
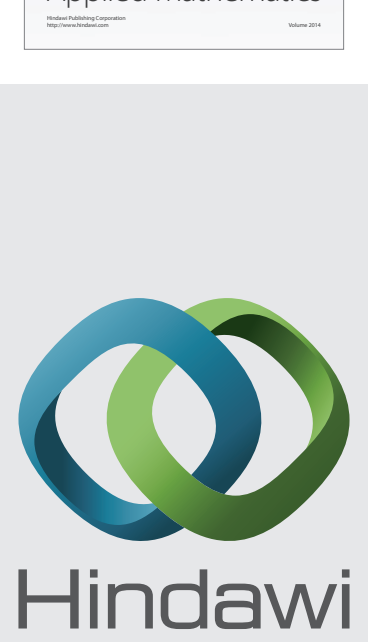

Submit your manuscripts at http://www.hindawi.com
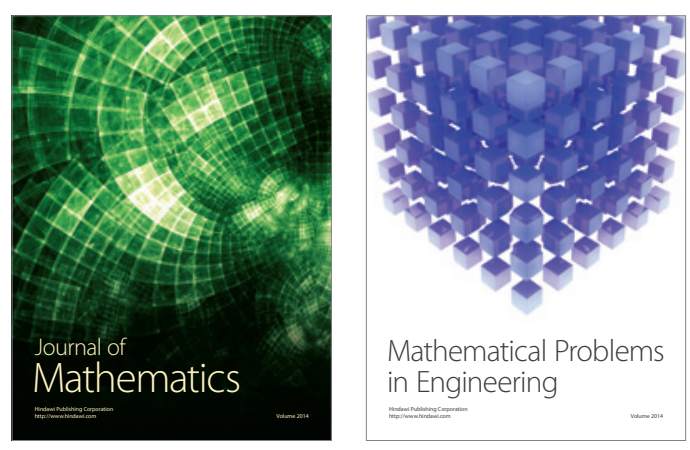

Mathematical Problems in Engineering
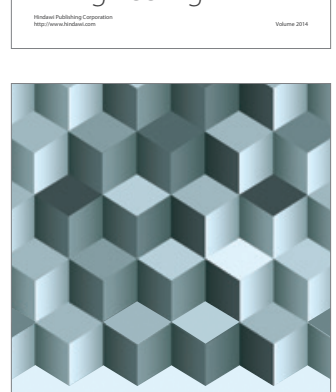

Journal of

Function Spaces
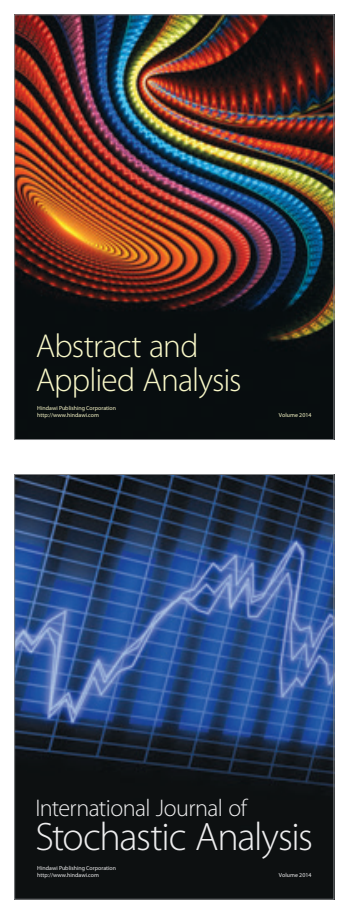

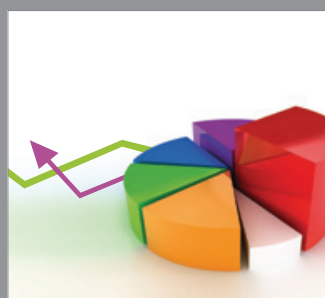

ournal of

Probability and Statistics

Promensencen
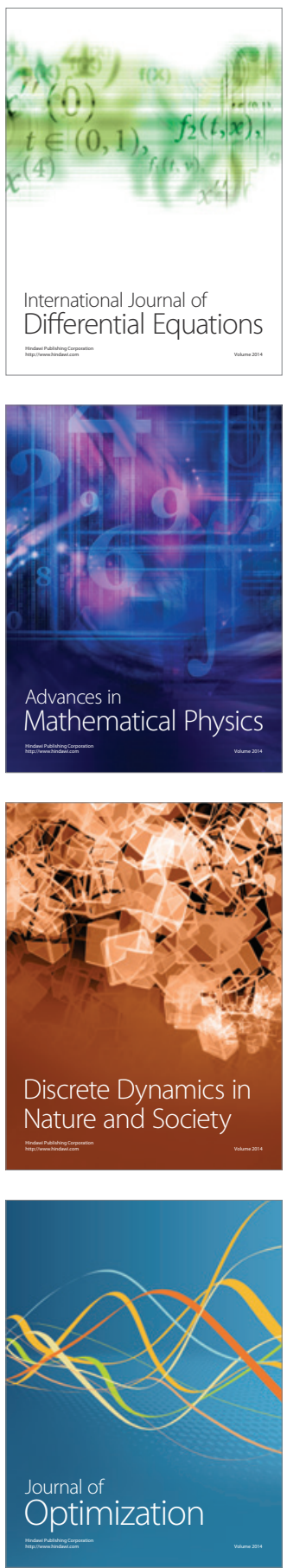